\title{
Colonic Tuberculosis. An Unusual Endoscopic Diagnosis
}

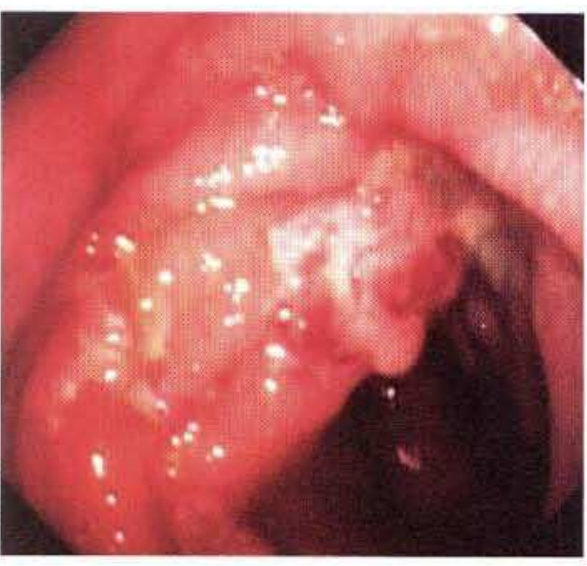

Figure 1: A patient with colonic tuberculosis. Colonoscopy shows two ulcers within a hyperemic nodular mucosa in the proximal colon.

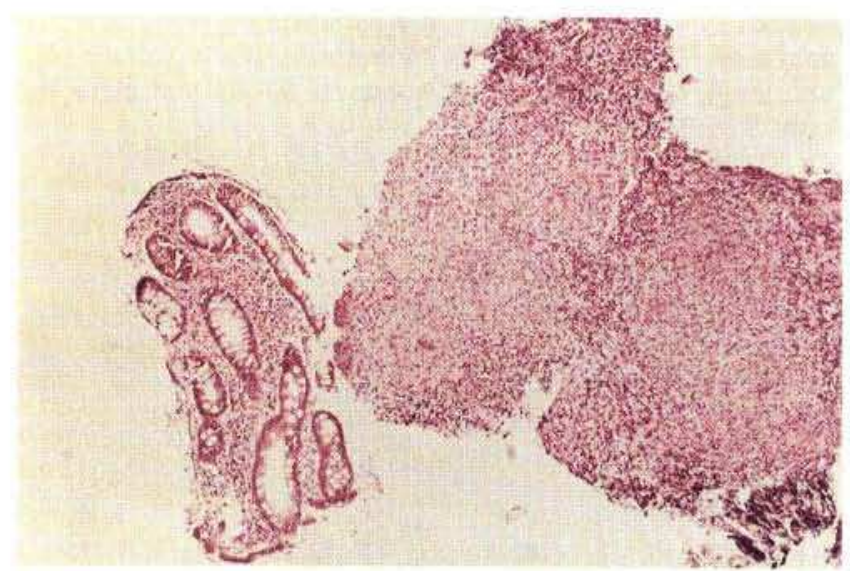

Figure 2: Histology of colonic mucosa ( $H$ \& E, magnification $\times$ 400) showing two non-caseating granulomas with epithelioid and giant cells.

The incidence of tuberculous infection has decreased in the Western World over the last decades, although lately a reemergence has been described (1). The large bowel can also be involved (2), but this is a rare finding. A 55-year-old woman was admitted for diarrhoea and nonspecific abdominal pain, and with a suspected childhood history of tuberculous pleuritis and peritonitis: physical examination was normal. Her hemoglobin was $11.9 \mathrm{~g} / \mathrm{dl}$ with normal red blood count indices, all other laboratory data being normal. On colonoscopy there were two irregular shallow ulcers within a hy- peremic and nodular mucosa located at the ileocecal valve and in the adjacent cecum (Figure 1). The histologic specimens showed some non-caseating granulomas with Langerhans type giant cells (Figure 2). Roentgenographic examination of the small intestine and chest $\mathrm{x}$-ray were normal. Tuberculin skin test and bacteriologic examination of the sputum were negative. Finally, the histological study biopsies taken during repeat colonoscopy revealed acid-fast bacilli and Mycobacterium tuberculosis was identified on culture. The patient was then successfully treated with isoniazid, rifampin and ethambutol.

The diagnosis of colonic tuberculosis can be difficult $(2,3)$. The clinical data can be misleading and frequently this condition can exist without respiratory disease, making the diagnosis difficult. At present, colonoscopy is considered the best diagnostic tool, although the endoscopic appearance (ulcerated areas, hyperemic nodular friable mucosa, stenotic areas with polypoidal mucosal lesions) can mimic several diseases, especially Crohn's disease or carcinoma of the colon (3-5). Colonic tuberculosis can only be reliably diagnosed when acid-fast bacilli, caseating granulomas on histology or Mycobacterium tuberculosis on culture of the specimens are found, although results are frequently unsatisfactory (5). The diagnosis of colonic tuberculosis remains a challenge, but it is important to consider this uncommon disease in the differential diagnosis of endoscopic abnormalities.

\author{
M. Gómez-Rubio ${ }^{(1)}$, B. de Cuenca (l), V. Opio(l), \\ J. Ulloa(l), J. Garciafl) \\ (I) Department of Gastroenterology and \\ (2) Department of Pathology \\ Getafe University Hospital \\ Complutense University \\ Carretera de Toledo $\mathrm{Km} \mathrm{12,500}$ \\ 28905 Getafe - Madrid, Spain
}

\section{References}

I. Snider DE, Roper WL: The new tuberculosis. N. Engl. J. Med. 1992; 326: $703-705$.

2. Gorbach SL: Infectious diarrhea. Tuberculosis of the gastrointestinal tract. In: Sleisenger MH, Fordtran JS (eds.): Gastrointestinal disease. Pathophysiology, Diagnosis, Management. 4th Edition. WB Saunders Company, Philadelphia, 1989: 1221-1224.

3. Shah S. Thomas V. Mathan $M$ et al.: Colonoscopic study of 50 patients with colonic tuberculosis. Gut 1992: 33: 347-351.

4. Aoki G, Nagasako K, Nakae Y et al.: The fibercolonoscopic diagnosis of intestinal tuberculosis. Endoscopy 1975: 7: 113-121.

5. Morgante PE, Gandara MA, Sterle E: The endoscopic diagnosis of colonic tuberculosis, Gastrointest. Endosc. 1989: 35: 115-118. 